
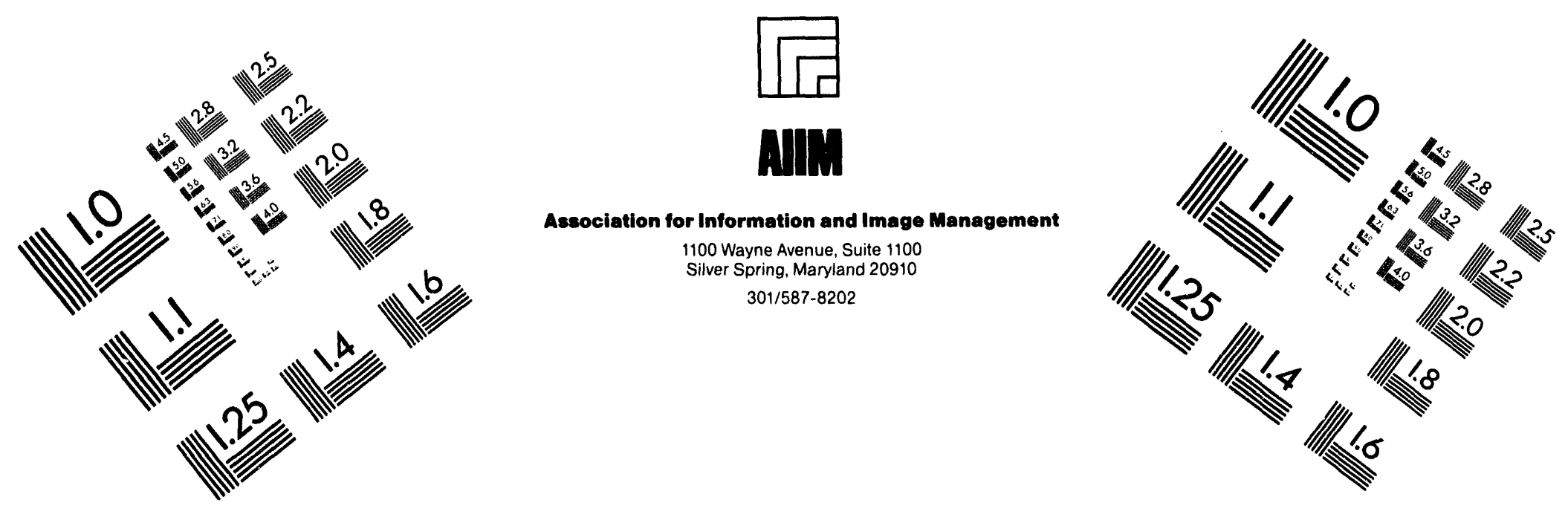

\title{
Centimeter
}

Lundmum

Inches
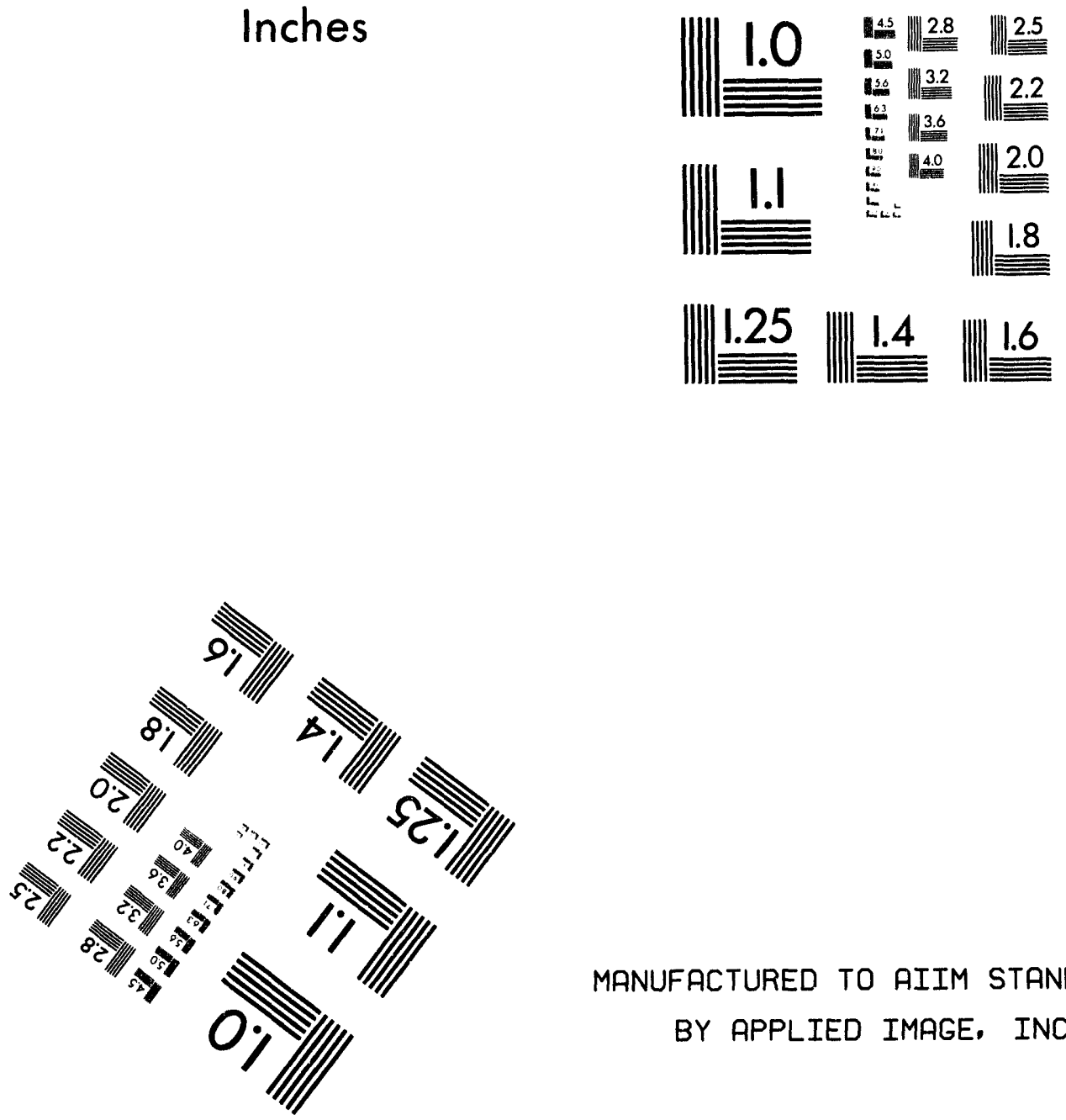

MANUFACTURED TO AIIM STANDARDS

BY APPLIED IMAGE, INC.

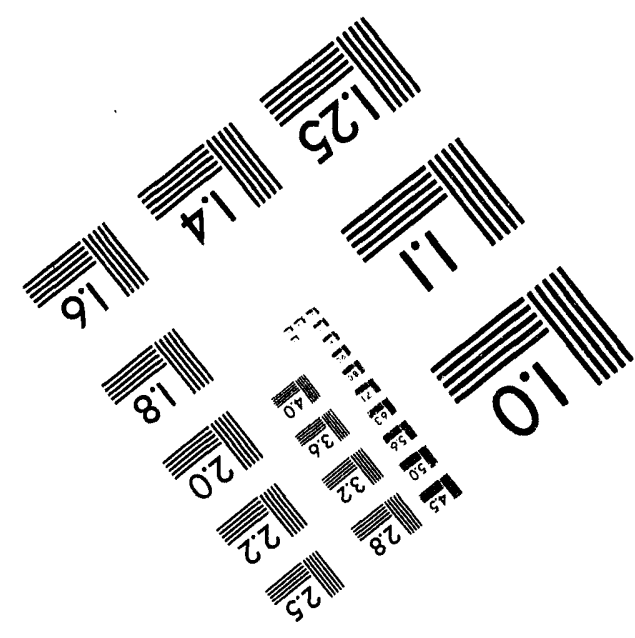



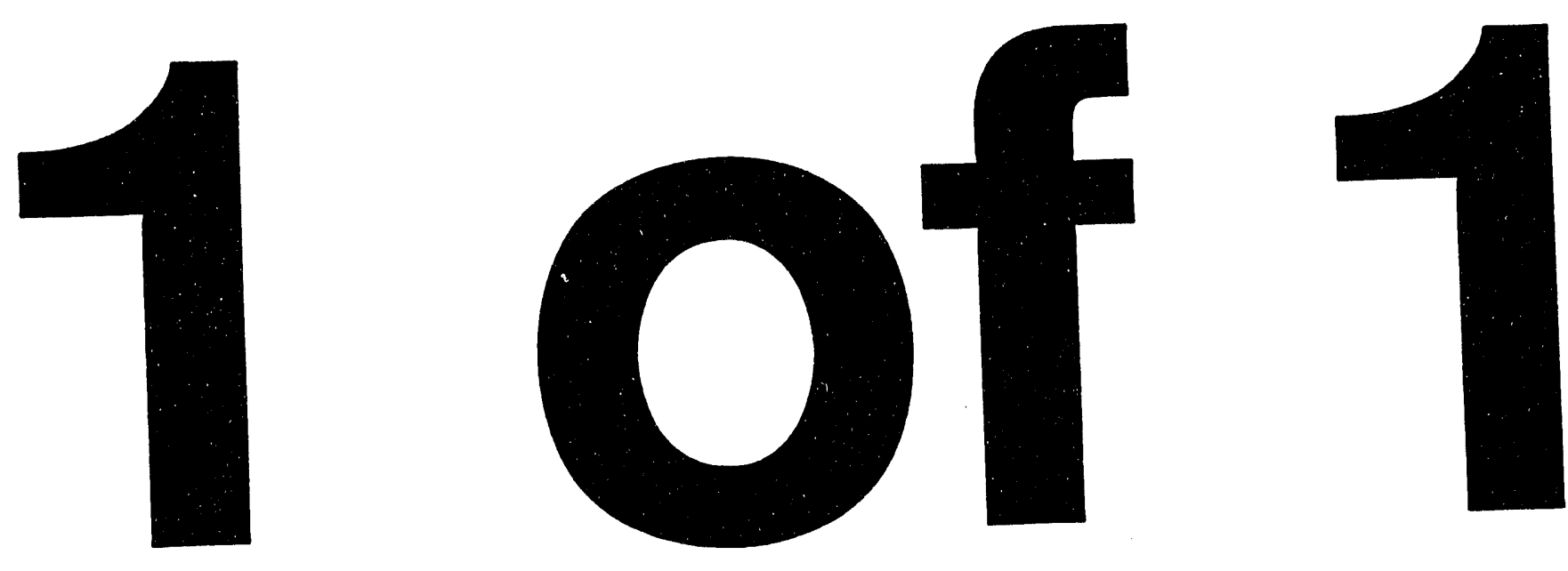


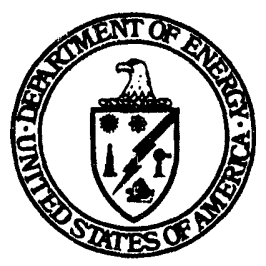

\section{OCRWM Procedure for Reporting Software Baseline Change Information Revision 0}




\section{OFFICE OF CIVILIAN RADIOACTIVE WASTE MANAGEMENT BASELINE MANAGEMENT PROCEDURE}

Title: OCRWM PROCEDURE FOR REPORTING SOFTWARE BASELINE CHANGE INFORMATION

Procedure No.:

A00000000-00811-5000-00005

\begin{tabular}{|c|l|l|}
\hline $\begin{array}{c}\text { Revision: } \\
00\end{array}$ & $\begin{array}{l}\text { Date: } \\
6 / 3 / 94\end{array}$ & $\begin{array}{c}\text { Page: } \\
1 \text { of } 6\end{array}$ \\
\hline & $\begin{array}{c}\text { Approvel: } \\
\text { RW-30 }\end{array}$
\end{tabular}

The purpose of this procedure is to establish a requirement and method for participant organizations to report software baseline change information to the M\&O Configuration Management (CM) organization for inclusion in the OCRWM Configuration Information System (CIS). (The requirements for performing software configuration management (SCM) are found in the OCRWM Quality Assurance Requirements and Description (QARD) document and in applicable DOE orders, and not in this procedure.) This procedure provides a linkage between each participant's SCM system and the CIS, which may be accessed for identification, descriptive, and contact information pertaining to software released by a participant. Such information from the CIS will enabie retrieval of details and copies of software code and documentation from the participant SCM system.

\subsection{APPLICABILTYY}

This procedure applies to scientific and engineering software baselined for release and which satisfies one or more of the following categories:

a) software approved for use in quality affecting work (QAW)

b) software which resides on an OCRWM Program shared resource

c) software which provides data exchange with other participant systems.

\subsection{DEFINITIONS}

Definition of standard terms used in this procedure and not defined in this section may be found in DOE/RW-0333P, Quality Assurance Requirements and Description (QARD) and in DOE/RW-0416, OCRWM Baseline Management Procedure for Document Identifiers.

3.1 Participant - Any OCRWM organization or OCRWM contractor performing work in support of the CRWMS. 


\begin{tabular}{|l|l|c|c|}
\hline $\begin{array}{l}\text { OCRWM PROCEDURE FOR } \\
\text { REPORTING SOFTWARE BASELINE } \\
\text { CHANGE INFORMATION }\end{array}$ & $\begin{array}{l}\text { Procedure No.: } \\
\text { A00000000-00811-5000-00005 }\end{array}$ & $\begin{array}{c}\text { Revision: } \\
00\end{array}$ & $\begin{array}{c}\text { Page: } \\
2 \text { of } 6\end{array}$ \\
\hline
\end{tabular}

4.0 RESPONSIBILITIES

4.1 Associate Director, Program Management and Integration - The Associate Director for Program Management and Integration (RW-30) is responsible for the preparation and modification of this procedure.

4.2 Team Leader, Configuration Management - The Team Leader, Configuration Management (RW37 ) is responsible for the implementation of this procedure.

4.3 Participant SCM Organizations - Each participant SCM organization shall report software baseline changes in accordance with the requirements and methods established in this procedure.

4.4 Participant CM Organizations - Each participant CM organization shall determine the appropriate Document Identifier (DI) for software configuration items reported on the OCRWM Software Baseline Change Information Form (Attachment 1). (The requirement for a participant $\mathrm{CM}$ organization is established in DOE/RW-0415, OCRWM Baseline Management Procedure for Configuration Item (CI) and CI Identifiers, Section 4.5.) The participant CM organization shall be responsible for resolving discrepancies between the information reported on the form and existing information in the CIS. The participant CM organization shall also be responsible for entering the data on the form into the CIS and forwarding a copy of the completed form to the submitting SCM organization, or for forwarding the form to the M\&O Configuration Management Organization for data entry into the CIS.

4.5 M\&O CM Organization - The M\&O CM organization shall accept the OCRWM Software Baseline Change Information Form from a participant who does not have CIS data entry capability, and shall enter the data on the form into the CIS and forward a copy of the completed form to the submitting SCM organization.

\subsection{PROCESS}

\subsection{FORM SUBMISSION}

5.1.1 Each participant SCM organization shall complete an OCRWM Software Baseline Change Information Form for each software item baselined for release in the participant's SCM system. The form shall be submitted to the participant CM organization within 10 working days of the baseline date. The initial forms shall be completed within 30 working days of the effective date of this procedure.

5.1.2 Subsequently, when a released version of a software baseline is changed in a participant SCM system, the SCM organization shall submit a Software Baseline Change Information Form to the participant $\mathrm{CM}$ organization within 10 working days of the baseline change date. 


\begin{tabular}{|l|l|c|c|}
\hline OCRWM PROCEDURE FOR & Procedure No.: & Revision: & Page: \\
REPORTING SOFTWARE BASELINE & A00000000-00811-5000-00005 & 00 & 3 of 6 \\
CHANGE INFORMATION & & & \\
\hline
\end{tabular}

\subsection{FORM VERIFICATION AND COMPLETION}

Upon receipt of a Software Baseline Change Information Form, the participant CM organization shall search the CIS (or request that a search be made) to determine if a software item has previously been entered in the CIS which matches the "Internal Software ID" identified on the form. Then:

a) If a maich is found in the CIS for the Internal Software ID, the CIS data shall be compared with that on the form. If discrepancies are found, they shall be resolved with the submitter and the form corrected. If no discrepancies are found, the form shall be completed, if necessary, with the data from the CIS, and the form shall then be submitted for data entry into the CIS.

b) If no match is found in the CIS for the Internal Software $\mathrm{D}$, the form shall be checked to ensure that all required information has been entered on the form, and discrepancies shall be resolved with the submitter. Then the following steps shall be performed:

1) If the DI entry on the form has been filled in by the submitter, the CIS database shall be searched to ensure the DI has not previously been used for another software item. If a discrepancy is found, it shall be resolved with the submitter. If no discrepancy is found, the form shall be submitted for data entry into the CIS.

2) If the DI entry on the form has not been filled in by the submitter, the DI shall be established by the participant CM organization, entered on the form, and the form submitted for data entry into the CIS.

\subsection{DATA ENTRY INTO THE CIS DATABASE}

5.3.1 The participant CM organization shall, within 10 working days of receipt of the form, enter the data on the form into the CIS or, if data entry into the CIS is not available at the participant site, shall forward the form to the M\&O Configuration Management organization for data entry into the CIS.

5.3.2 Upon completion of data entry into the CIS, a copy of the form, with the completed data entry information, shall be sent to the submitting SCM organization.

\section{U. S. DEPARTMENT OF ENERGY} W.ASHINGTON. D.C. 


\begin{tabular}{|l|l|c|c|}
\hline $\begin{array}{l}\text { OCR WM PROCEDURE FOR } \\
\text { REPORTING SOFTWARE BASELINE } \\
\text { CHANGE INFORMATION }\end{array}$ & $\begin{array}{l}\text { Procedure No.: } \\
\text { A00000000-00811-5000-00005 }\end{array}$ & $\begin{array}{c}\text { Revision: } \\
00\end{array}$ & $\begin{array}{c}\text { Page: } \\
4 \text { of } 6\end{array}$ \\
\hline
\end{tabular}

\section{OCRWM SOFTWARE BASELINE CHANGE INFORMATION FORM}

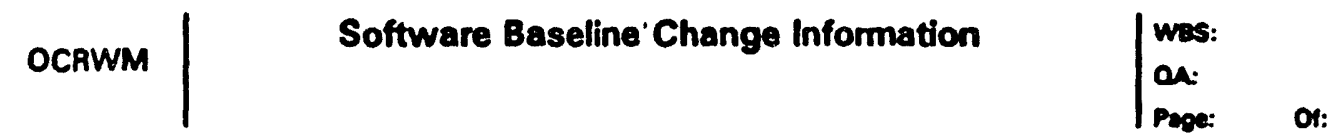

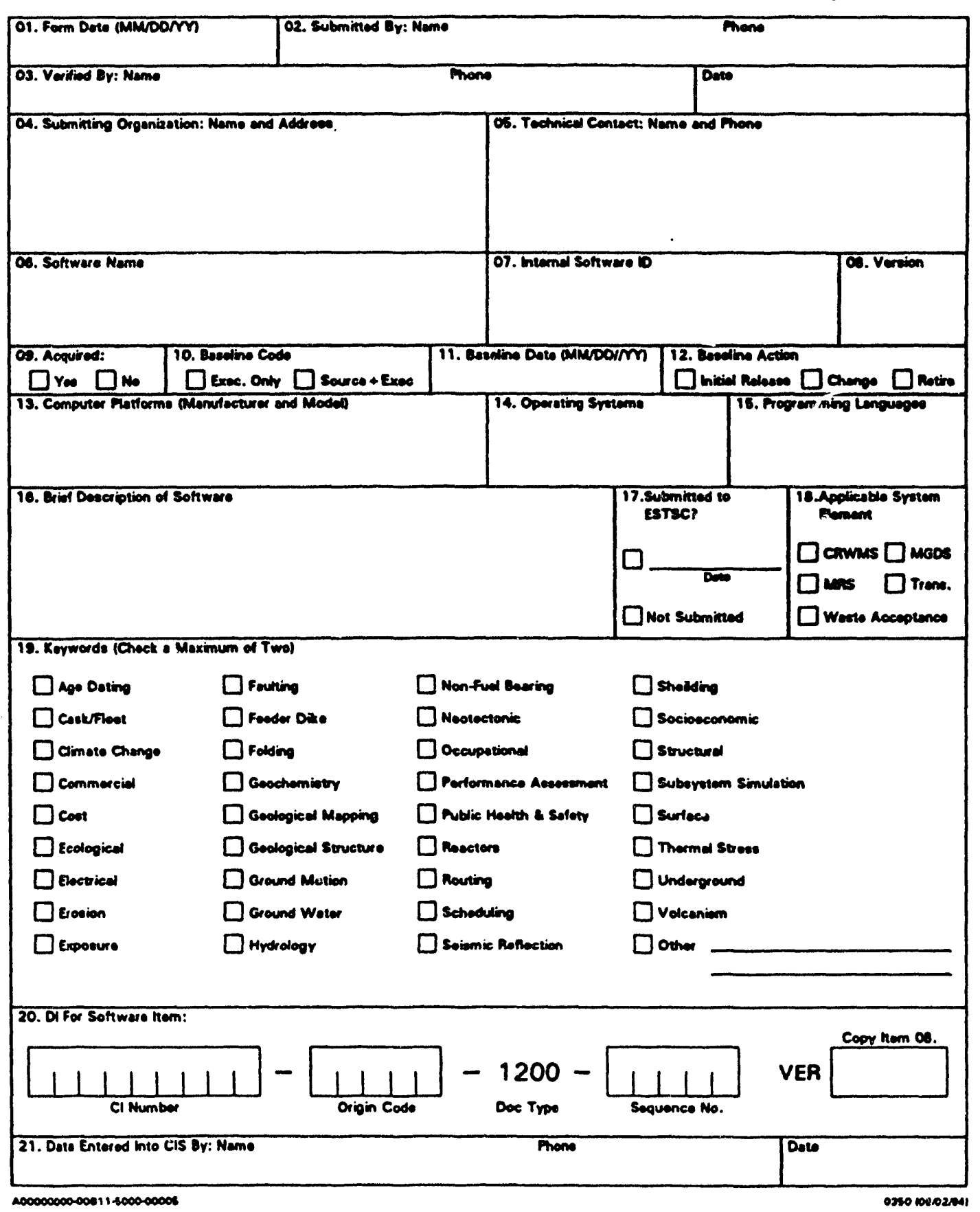




\begin{tabular}{|l|l|c|c|}
\hline $\begin{array}{l}\text { OCRWM PROCEDURE FOR } \\
\text { REPORTING SOFTWARE BASELINE } \\
\text { CHANGE INFORMATION }\end{array}$ & $\begin{array}{l}\text { Procedure No.: } \\
\text { A00000000-00811-5000-00005 }\end{array}$ & $\begin{array}{c}\text { Revision: } \\
00\end{array}$ & $\begin{array}{c}\text { Page: } \\
5 \text { of } 6\end{array}$ \\
\hline
\end{tabular}

\section{ATTACHMENT I (Continued) \\ OCRWM SOFTWARE BASELINE CHANGE INFORMATION FORM}

\section{FORM INSTRUCTIONS}

1. Type or print the date the form is filled in.

2. Type or print the name and phone number of the person submitting the form.

3. Type or print the name and phone number of the person verifying the information on the form against the information in the CIS database. Type or print the date the form is verified.

4. Type or print the name and address of the submitting organization.

5. Type or print the name and phone number of the technical contact for the software item.

6. Type or print the name of the software as identified in the participant's SCM system.

7. Type or print the software identifier as designated in the participant's SCM system (this may be the same as the DI for the software, depending on the participant's procedures).

8. Type or print the version number of the software as designated in the participant's SCM system.

9. If the software was originally acquired by the participant, enter a "Y"; otherwise, enter an "N".

10. If the baseline code consists of executable code only, check the first box. If the baseline code consists of source plus executable code, check the second box.

11. Enter the baseline date for the action designated in item 12 .

12. Check the appropriate box.

(For items 13-18. if these fields were filled in on a previous submission and no changes are required, you may enter "see CIS" and draw a diagonal line from box 13 through box 18 . However, if changes are required. enter the changes as necessary in the appropriate boxes, and "see CIS" in the remaining boxes.)

13. Type or print the computer platform(s) required to execute the software.

14. Type or print the operating system(s) required to execute the sofmare. 


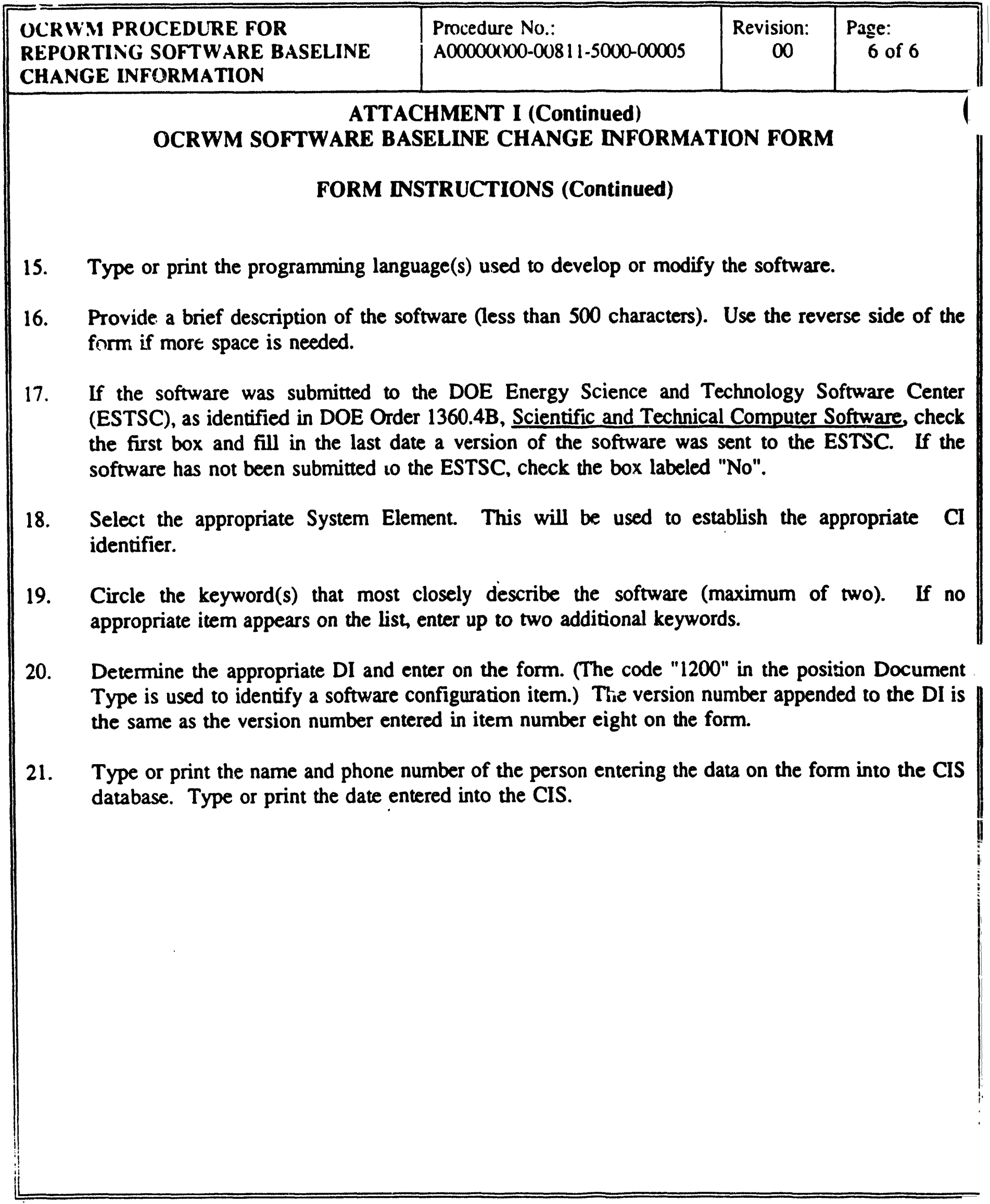



